\title{
MATHEMATICAL MODELS OF INTERFERENCE BETWEEN THE LEVELS OF ENVIRONMENTAL CONTAMINATION AND REGIONAL INDUSTRIAL GROWTH
}

\author{
Angelina Ilchenko' ${ }^{1}$ Dr. Sc. (Econ.), Prof.; Luo Juan ${ }^{2}$, Cand. Sc. (Econ.) and \\ Alexander Krovyakov ${ }^{3}$, Cand. Sc. (Econ.) \\ ${ }^{1}$ Honoured Science Worker of the Russian Federation, Director of the Center for Innovative and Anti-Crisis \\ Technologies of Ivanovo State University of Chemistry and Technology, ${ }^{2}$ Luo Juan, Teacher of the Mathematics \\ and Computer Science College of Wuhan Textile University, Wuhan City, Hubei Province, China, ${ }^{3}$ Ivanovo State \\ University of Chemistry and Technology,
}

\begin{abstract}
In article the theoretical substantiation of a complex of models of the coordinated regional development is resulted, from a position of an ecological condition and economic growth, on purpose to show possibilities of use for the quantitative analysis and forecasting (allocation of tendencies of regional development of preservation of the environment - for recommendations about regional government).

For the first time the modified model "Ecological curve of the Smith" - for the interrelation analysis between environmental contamination and per capita population incomes (taking into account an inequality in incomes) is formulated. The structured model of vector autoregression for reflection of dynamic character of interrelation between ecological pollution and well-being of the population is offered. The model of decomposition of effect from emissions of a waste is structurally expanded at the expense of demographic factor. The offered models unite in a uniform complex of the analysis and forecasting, through system of estimated relative indexes, for the description of degree of synchronization of economic and ecological development of territory.
\end{abstract}

Key words: sustainable economic development, ecological curve, model for decomposition of the environmental contamination, VAR model of dynamic coordination.

JEL code: $\mathrm{O} 44$

\section{Introduction}

Since entering the era of industrial society, humanity has succeeded in economic development. In conditions of the economic globalization, an adequate increase in resource costs and the release of waste into the planet's environment are caused by industrial expansion and urbanization. Since the 1960s, environmental degradation connected with economic development has attracted a lot of attention from scientists around the world. For example, in 1962, Rachel Carson, in his work "Silent Spring", discussed the growing dangers of pesticides and chemicals such as DDT. In 1972, a group of economists - members of the Club of Rome published a report "Limits of Growth". The report said that population growth, investment, food production lead to depletion of resources and pollution of the environment - this is an exponential growth. It also was stressed, that with such trend, economic growth will reach its limit in 100 years. In 1972, the first United Nations Conference on the Human Environment was held. It proposed the slogan "Only One Earth", and this was the first milestone in understanding the history of human sustainable development. In 1987, the theme of the global environment was presented in the report of the United Nations World Commission on Environment and Development (WCED) "Our Common Future" at the UN General Assembly, which proposed the formulated concept of sustainable development. In 1992, The World Bank published a World Development Report on "Development and the Environment", and the corresponding "Local Agenda 21" was adopted in the same year. In 2009, the world countries signed a new agreement about urgent measures, in connection with the future climate change, at the Conference on Global Warming convened under the auspices of the UN in Copenhagen. In 2015, the United Nations Climate Change Conference in Paris adopted the version of the Paris Agreement to reduce carbon dioxide emissions until 2030.

Although China is at the stage of rapid growth of its economy, since the period of reforms and openness, yet traditional development models: "high costs, high consumption, high pollution, while low quality, low efficiency, low output", or: "pollution first, recovery later"; "first destruction, then 
reconstruction" - they are still dominant. The list of the main environmental contamination sources in China is well known - air pollution, water pollution, solid waste incineration, soil contamination, soil erosion, and so on. The relative lack of resources, the vulnerability of the ecological environment, the insufficient capacity of the environmental recovery industry - are becoming an important factor limiting China's sustainable economic development (Yanging X., 2010). Hubei Province is the most important industrial region in Central China, located in the basin of the Yangtze River. Along with the full implementation of the China general strategy for Hubei as a central industrial area, Hubei has unique opportunities for accelerated development. However, the rapid growth rate depends on a large number of factors, the combined effect of which affects the production of thermal energy and the industries with intensive pollution.

The aim of the present research is to describe relations between socio-economic factors and the environmental contamination at the country level on the basis of economic and mathematical modelling and propose methods and algorithms for an empirical justification of relevant government policies for environmental protection of highly industrialized regions.

The main tasks of the research are to define effects of regional per capita income gap on different types of environmental pollution; to establish the long-term dynamic effect between GRP and environmental contamination factors; to prove the necessity of including demographic effect as a source of environmental contamination factor together with scale, structural and technological effects.

The object of research is the state of economy and the level of environmental contamination in the industrialized region of China - Hubei Province.

\section{Research results and discussion}

1. A modified Environmental Kuznets Curve (EKC) model for analysing the relationship between per capita incomes and environmental pollution, taking into account income inequality

The EKC model shows (Fig. 1) that if the average per capita income is low, then the degree of environmental pollution is lower. With increasing per capita income, environmental pollution becomes serious. Environmental degradation is complicated by economic growth. When economic development reaches a certain level, that is, a critical point, or "inflection point", with subsequent increase in average per capita income, environmental pollution again becomes lower, the quality of the environment gradually improves. This situation can be described with an inverted U-shaped curve to describe the relationship between pollution and income. The EKC model was put forward by Grossman as a quadratic function. Looking at the opinions of domestic and foreign scientists, we found that there is no need for an inverted $\mathrm{U}$-curve to describe the relationship between pollution and income in some regions and countries (Yanging $X_{.}, 2010$ ). Thus, there is no urgent need to use a quadratic function to reflect the relationship between pollution and income levels. The authors first used a cubic curve in the form of a logarithm to describe the relationship between average per capita income " $x$ " and environmental pollution " $y$ " for formula (1).

$$
\ln y=\beta_{0}+\beta_{1} \ln x+\beta_{2}(\ln x)^{2}+\beta_{3}(\ln x)^{3}+\varepsilon
$$

Where:

$\beta_{0}, \beta_{1}, \beta_{2}, \beta_{3}$ - estimated parameters. The following options are possible:

(I) $\beta_{1}>0\left(\beta_{1}<0\right), \beta_{2}=\beta_{3}=0$, Inx и Iny - linear relationship; 
(II) $\beta_{3}=0, \beta_{2}<0, \ln \times$ и Iny - inverted U-shaped relationship;

(III) $\beta_{3}=0, \beta_{2}>0$, Inx и Iny - U-shaped relationship;

(IV) $\beta_{3}>0, \beta_{2}^{2}-3 \beta_{1} \beta_{3}>0, \ln x$ и Iny - N-shaped relationship;

$\beta_{3}>0, \beta_{2}^{2}-3 \beta_{1} \beta_{3}<0, \operatorname{lnx}$ и Iny - ascending function;

(V) $\beta_{3}<0, \beta_{2}^{2}-3 \beta_{1} \beta_{3}>0$, the relationship of Inx and Iny is opposite to the $\mathrm{N}$-shaped;

$\beta_{3}<0, \beta_{2}^{2}-3 \beta_{1} \beta_{3}<0$, Inx and Iny is a decreasing function;

(VI) $\beta_{1}=\beta_{2}=\beta_{3}=0$, no relationship between Inx and Iny.

The authors used formula (1) and official China statistics over 15 years to analyse the relationship between the level of environmental contamination and average per capita income in Hubei Province. The authors researched whether there was a relationship between few indicators (PGRP- gross regional product (GRP) per capita, WWP-emission of industrial wastewater, WGPemission of industrial exhaust gas, SWP-emission of industrial solid waste) as an inverted U-shaped curve.

levels of environmental

contamination

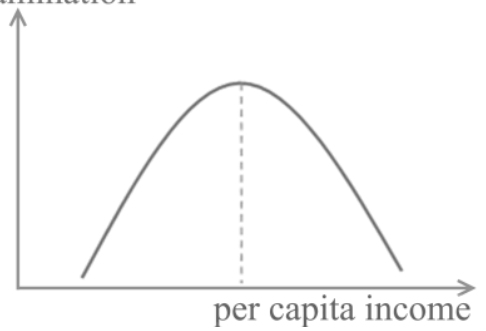

Fig. 1. The theoretical relationship between income and environmental contamination in Environmental Kuznets Curve model

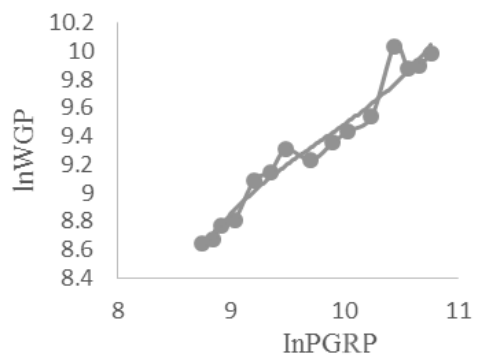

Source: authors' calculations based on China official statistics

Fig. 3. The identified relationship between GRP per capita and emission of industrial exhaust gas in Hubei Province in 2000-2014

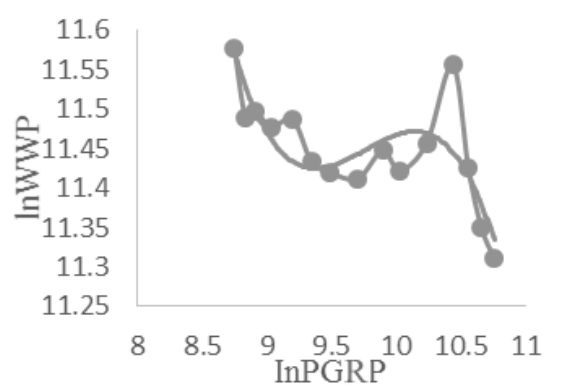

Fig. 2. The identified relationship between GRP per capita and emission of industrial wastewater in Hubei Province in 2000-2014

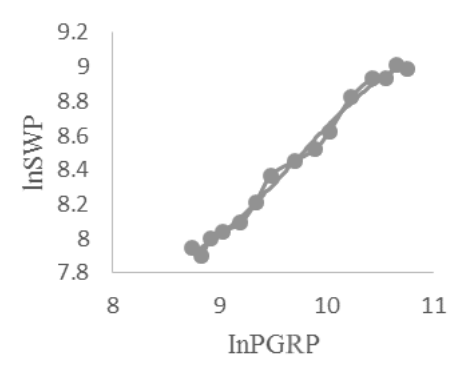

Fig. 4. The identified relationship between GRP per capita and emission of industrial solid waste in Hubei Province in 2000-2014

For Fig. 2, it can be seen that in Hubei province, the relationship of the inverted $\mathrm{N}$-curve exists between GRP per capita and industrial wastewater. That is, with an increase in per capita GRP, the release of wastewater first decreases, then increases and decreases again. For Fig. 3 and Fig. 4, we can see that the emission of industrial exhaust gas and solid waste has a constant increase with GRP per capita. The classical relationship of the inverted $\mathrm{U}$-curve between the economy and the environment in Hubei province has not been established. 
The authors first used a cubic curve in the form of a logarithm to describe the relationship between average per capita income $X$ and environmental contamination $Y$ in the form of formula (1). Among the six variants of the relations between $X$ and $Y$ there is an EKC model, as a special case.

In recent years, the problem of income inequality has been increasing in many regions of China. Therefore, the authors took into account the income inequality in the model (the Gini coefficient). The auhors built the following model, using variables such as income, income gap and environmental contamination levels:

$$
\ln y=\mathrm{a}+\mathrm{b} \ln \mathrm{x}+\mathrm{c}(\ln \mathrm{x})^{2}+\mathrm{d}(\ln \mathrm{x})^{3}+\mathrm{e} * \mathrm{GINI}+\mathrm{f} *(\mathrm{GINI} * \ln \mathrm{x})+\varepsilon
$$

Where:

a, b, c, d, e, f - estimated parameters;

GINI - the Gini coefficient;

GINI*Inx - interaction effect (the econometric concept put forward by J.M. Wooldridge (Yanging X., 2010).

The authors used the formula (2) and the statistical data of Hubei Province to obtain the relationship between InPGRP, GINI and InWWP, InWGP, InSWP and then computed the partial derivatives and thus got the following formula (Juan L., 2013):

$$
\begin{aligned}
& \frac{\partial \ln W W P}{\partial \mathrm{GINI}}=7.51-0.88 * \ln P G R P \\
& \frac{\partial \ln W G P}{\partial G I N I}=-39.24+4.16 * \ln P G R P \\
& \frac{\partial \ln S W P}{\partial G I N I}=19.00-1.99 * \ln P G R P
\end{aligned}
$$

It can be seen that an increase in income inequality can reduce water pollution; the growth in the income gap can increase air pollution. And the higher the income gap, the greater the impact of this factor. Increasing income inequality can also reduce the release of solid waste.

Summarizing the foregoing, it can be noted that the income gap has different effects on different types of pollution, the overall result of this influence is not defined. Sometimes the government can reduce income inequality through economic policies, for example, aimed at producing products that increase total resources. The government can also promote the development of enterprises in small towns to narrow the gap between urban and rural areas. But such a policy will inevitably lead to new pollution of the environment, so the government must strictly control the impact of income inequality on all types of pollution. Thus, state interventions can contribute to sustainable economic development.

\section{Including in the VAR-model of the current values of endogenous variables}

It is proposed to include in the VAR model the current values of endogenous variables to analyse the relationship between average per capita incomes and environmental contamination using the newly obtained and structured SVAR model.

The principle of the vector autoregression (VAR) model is to use each internal variable as a function of all internal lagging variables. The model can be used to predict time series and analyse dynamic effects of random noise on the system (Aivazyan S.A., 2010).

A mathematical representation of the model VAR $(p)$ : 


$$
Y_{t}=\Phi_{1} Y_{t-1}+\cdots+\Phi_{p} Y_{t-p}+\varepsilon_{t} \quad t=1,2 \cdots T
$$

Where:

$Y_{t}$ : a column vector $\mathrm{k}$ of measurable endogenous variables;

$p$ : lagged order;

$\mathrm{T}$ : sample size;

$\Phi_{1}, \cdots \Phi_{p}$ : - matrix of estimated coefficients ( $\mathrm{k} \times \mathrm{k}$ matrix);

$\varepsilon_{t}:$ random disturbance, column vector of $\mathrm{k}$ measured variables.

The authors research a modified structural model VAR (SVAR) containing explicitly the current values of endogenous variables (Juan L., Ilchenko A. N., 2013).

The dynamic effect is of interest when the noise changes or the model is subjected to a certain influence.

Method applied is called Impulse Response Function (IRF). The authors have given an example of the results on the official statistics of Hubei Province (2000-2014). The VAR and SVAR models require that the variables of the time series to be stable. But GRP per capita data and data about environmental contamination are not stable, but their first-order differences are stable. Therefore, as a result, the authors constructed a model for industrial exhaust gas emission and per capita GRP as a model of SVAR (1) based on the first-order difference calculation data. Similarly, the authors made the SVAR model for emission of industrial wastewater, emission of industrial solid waste and their dependence on per capita GRP (Juan L., Ilchenko A. N., 2013).

$$
\left(\begin{array}{l}
\Delta \ln W G P \\
\Delta \ln P G R P
\end{array}\right)=\left(\begin{array}{l}
-21.55 \Delta \ln P G R P \\
6.47 \Delta \ln W G P
\end{array}\right)+\left(\begin{array}{rr}
-1.398 & 11.268 \\
3.004 & -6.202
\end{array}\right)\left(\begin{array}{l}
\Delta \ln W G P(-1) \\
\Delta \operatorname{lnPGRP}(-1)
\end{array}\right)+\left(\begin{array}{l}
1.760 \\
0.127
\end{array}\right)+\left(\begin{array}{l}
\mathrm{u}_{11} \\
\mathrm{u}_{21}
\end{array}\right)
$$

Where:

$\Delta \operatorname{lnWGP}$ и $\Delta \operatorname{lnPGRP}$ - first-order differences.

Formula (7) shows relationship between $\Delta \ln W G P, \Delta \ln P G R P, \Delta \ln W G P(-1)$ и $\Delta \ln P G R P(-1)$. The authors introduced the functions of the impulse response and the decomposition of the variance (Fig. $5-7)$.

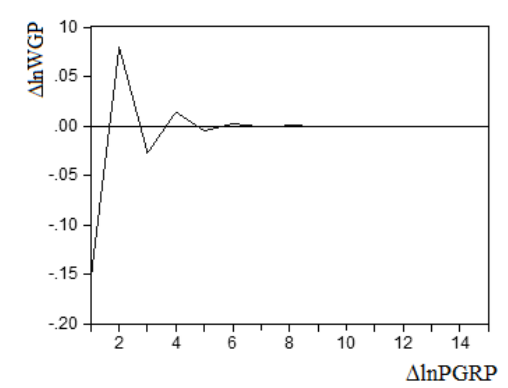

Source: authors' calculations based on China official statistics

Fig. 5. The indentified impulse of the exhaust gas emission function from per capita GRP in Hubei Province in 2000-2014

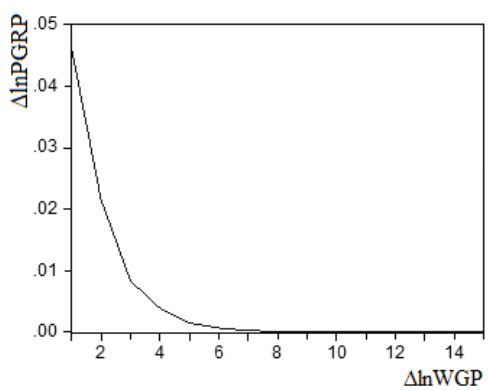

Fig. 6. The identified impulse of per capita GRP function from the exhaust gas emission level in Hubei Province in 20002014

In Figure 5, it is seen that with increasing economic growth, emissions into the atmosphere are rapidly gaining volumes, and then become smaller, after that more and less again, and ultimately stabilize. The increase in average per capita income will lead to fluctuations in air pollution and 
stabilize after the seventh period, which reflects the negative impact of per capita income on air pollution.

In Fig. 6 , it is seen that with the increase in emissions to the atmosphere, economic growth is rapidly declining, and ultimately stabilizing. This shows that air pollution slows down economic development.

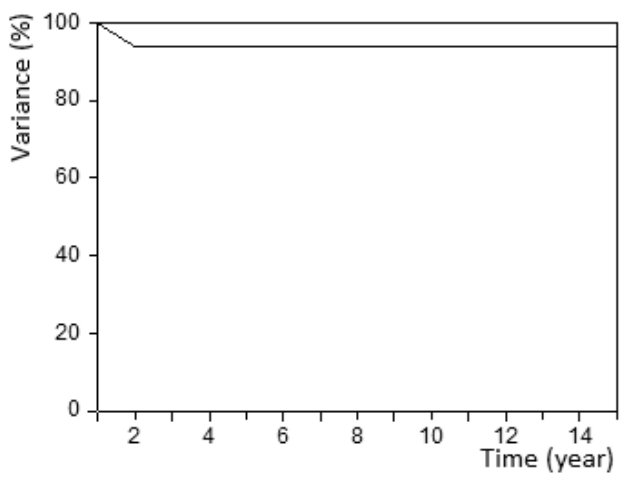

Source: authors' calculations based on China official statistics

Fig. 7. Calculated variance of the percentage of industrial exhaust gas emissions growth in relation to the growth of per capita GRP (Response variance curve, RVC) for Hubei Province in 2000-2014

In Fig. 7, the horizontal axis is time, the vertical axis is the degree of the relative contribution of the variance (\%). It is seen that the variance of the percentage of growth in industrial exhaust gas emissions, in relation to the growth of per capita GRP, is stable around $90 \%$ after the second period. This shows that economic growth has a huge impact on increasing air pollution. This reflects that the current state of economic growth in Hubei strongly depends on the investment climate, lack of technology, high energy consumption and environmental contamination. This does not lead to sustainable economic development. It is necessary to change the situation of economic growth, increase production efficiency and optimize the utilization of waste.

The new modified model SVAR allows to establish dependence of value of a variable from its own lags and lags of other variables. This allows one to make a structure that can cover more characteristics of the variable. The impulse response function can describe the effect of the system in case of noise changes, and analysis of the variance decomposition describes the degree of contribution of a particular burst. Thus, the model reflects the long-term dynamic effect between economic and environmental variables.

\section{Including of demographic factors in the decomposition model of the overall environmental contamination}

Grossman and Krueger (Juan L., Ilchenko A. N., 2014) note that economic growth can affect environmental contamination through three channels: the effect of scale, the structural effect and the technological effect. They formed the dynamic equations for the decomposition process of the influence factor of the waste produced. For China, the population reproduction is very important for social development. The large population of China affects the environment and economic development. Therefore, the authors added a demographic factor to the model (Figure 8). 


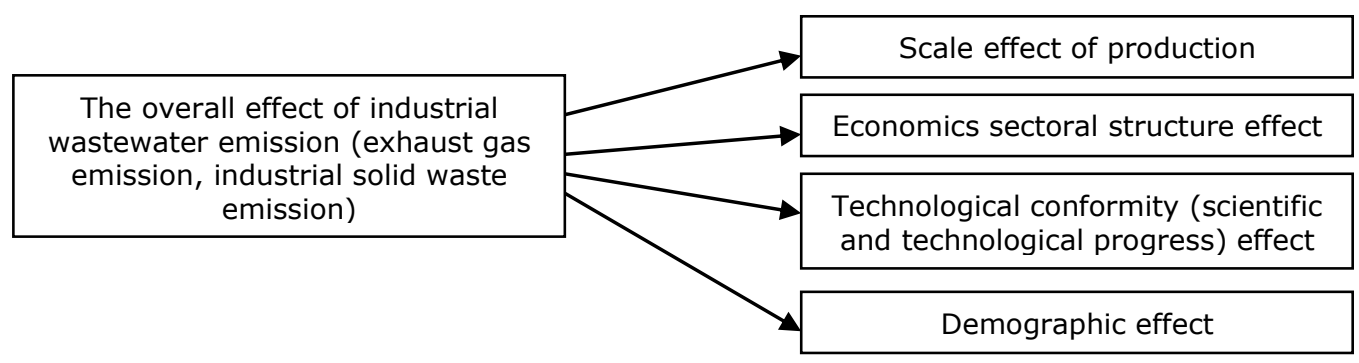

Fig. 8. Supposed by the authors scheme of decomposition of the environmental factor into sources of influence (economic reasons)

To analyse the decomposition of the environmental pollution factor into the influencing factors, the authors use the following model (suggested by the authors):

$$
E_{t}=\frac{Y_{t}}{P_{t}} P_{t} \sum_{j=1}^{3} \frac{E_{j t}}{Y_{j t}} \frac{Y_{j t}}{Y_{t}}
$$

Where:

$\mathrm{t}$ - observation period, years, $\mathrm{t}=1, \ldots 15$;

$j$ - structural groups of industries (spheres of activity) in terms of the degree of influence on pollution: agricultural, industrial, transport and services; $j=1,2,3$.

$E_{t}$ - waste emissions for the period t;

$Y_{t}-\mathrm{GDP}$;

$\mathrm{P}_{t}$ - population;

$E_{j t}$ - the waste emissions of the industry $\mathrm{j}$ for the period $\mathrm{t}$.

$Y_{j t}$ - industry's contribution to GDP $\mathrm{j}$ for the period $\mathrm{t}$.

$\frac{E_{j t}}{Y_{j t}}$ - intensity of industrial pollution for industry $\mathrm{j}$ for the period $\mathrm{t}$, marked as $I_{j t}$.

$\frac{Y_{j t}}{Y_{t}}$ - share of industry $\mathrm{j}$ in GDP, marked as $S_{j t}$.

$y_{t}$ used to reflect the per capita income $\frac{Y_{t}}{P_{t}}$.

The authors have carried out the necessary mathematical transformations to reveal the structure of the model (eJuan L., Ilchenko A. N., 2014). Thus, the level of pollution is determined by four economic factors that can be reflected as: $E_{T}-E_{\mathrm{T}_{0}}=\Delta E_{1}+\Delta E_{2}+\Delta E_{3}+\Delta E_{4}$. In the right side of the equation: the scale effect, the demographic effect, the structural effect and the technical effect. To calculate the integral, the authors use the Logarithmic Mean Division Index (LMDI) method. The logarithmic mean function is used as a weight.

Table 1 shows the results of the decomposition, using the example of contamination with industrial exhaust gas emission. Similarly, decomposition of the total pollution factor for industrial wastewater emission and industrial solid waste emission is calculated (Juan L., Ilchenko A. N., 2014). 
The authors' results of the decomposition of the general contamination factor, in terms of industrial exhaust gas emission in Hubei Province in 2000-2014 (Units: 100 million cubic meters)

\begin{tabular}{|c|c|c|c|c|c|}
\hline Year & $\begin{array}{c}\text { Scale effect } \\
\left(\Delta E_{1}\right)\end{array}$ & $\begin{array}{c}\text { Demographic effect } \\
\left(\Delta E_{2}\right)\end{array}$ & $\begin{array}{c}\text { Structural } \\
\text { effect }\left(\begin{array}{c}\Delta E_{3} \\
)\end{array}\right.\end{array}$ & $\begin{array}{c}\text { Technological } \\
\text { effect }\left(\begin{array}{c}\Delta E_{4} \\
)\end{array}\right.\end{array}$ & $\begin{array}{c}\text { Increase in } \\
\text { total }\end{array}$ \\
\hline $\mathbf{2 0 0 1}$ & 513.47 & 5.51 & 4.15 & -377.15 & 145.98 \\
\hline $\mathbf{2 0 0 2}$ & 481.08 & 22.17 & 2.45 & 114.34 & 620.05 \\
\hline $\mathbf{2 0 0 3}$ & 774.49 & 24.47 & 84.79 & -616.80 & 266.96 \\
\hline $\mathbf{2 0 0 4}$ & 1304.04 & 1.03 & 14.99 & 810.93 & 2130.99 \\
\hline $\mathbf{2 0 0 5}$ & 1456.88 & -26.17 & 449.91 & -1314.58 & 566.04 \\
\hline $\mathbf{2 0 0 6}$ & 1384.06 & 91.86 & 209.14 & -74.03 & 1611.03 \\
\hline $\mathbf{2 0 0 7}$ & 2073.88 & 81.57 & 51.22 & -3008.74 & -802.07 \\
\hline $\mathbf{2 0 0 8}$ & 2797.02 & -689.47 & 113.47 & -875.95 & 1345.07 \\
\hline $\mathbf{2 0 0 9}$ & 1599.68 & 18.95 & 455.63 & -1109.27 & 964.99 \\
\hline $\mathbf{2 0 1 0}$ & 2731.62 & 18.42 & 569.74 & -1977.78 & 1342.01 \\
\hline $\mathbf{2 0 1 1}$ & 3620.85 & 93.92 & 494.09 & 4765.52 & 8974.38 \\
\hline $\mathbf{2 0 1 2}$ & 2567.99 & 76.91 & 128.92 & -6101.06 & -3327.23 \\
\hline $\mathbf{2 0 1 3}$ & 1968.45 & 68.20 & -382.20 & -1180.60 & 473.85 \\
\hline $\mathbf{2 0 1 4}$ & 2111.00 & 60.98 & -1038.08 & 582.15 & 1716.05 \\
\hline
\end{tabular}

In work (Juan L., Ilchenko A. N., 2014), the hypothesis of the possibility of decomposition of the general polluting effect into economic system-forming factors - the scale effect of production, economics sectoral structure effect and technological conformity (scientific and technological progress) effect - is analysed. For the conditions of China, where the population is very large, the authors added demographic factors to the Grossman-Kruger model. The model for decomposition of environmental contamination thus included 4 economic factors: scale effect, demographic effect, structural effect and technological effect. Thus, the authors modified the Grossman-Krueger model and experimentally confirmed the validity of the set hypothesis.

\section{Conclusions}

The constructed complex of mathematical models, including a system of integrated appraisal indices, reflects the realities and opportunities for a balanced development of highly industrial territories, both from the standpoint of economic growth and ecology. The theoretical methodology for analysing the problem of the relationship between the economic indicators of the development of the territory and the factors of environmental protection, based on the modern apparatus of applied econometrics, also has promising practical application. The proposed methods, algorithms, methods provide an empirical justification for the formulation and implementation of relevant policies: sustainable economic development and environmental protection in the industrialized regions of different countries.

\section{Acknowledgments}

The article is prepared on the basis of the materials of the scientific project "Design of mathematical models for assessing the impact of the innovation infrastructure development scale on the upgrade of non-primary sectors of the Russian economy" (grant of the Russian Science Foundation 2018).

\section{Bibliography}

1. Aivazyan, S.A. Methods of Econometrics. M.: Magistr, 2010.

2. HDR - Human Development Report. United Nations Development Program. N.Y., 2000, 2001, $2002,2003$. (www.undp. org). 
3. Ilchenko, A.N. Economic and Mathematical Methods. - M.: Finansi i Statistika. - 2006.

4. Ilchenko, A.N., Ma Jun. Integral Assessment of the Level of Socio-economic Infrastructure Development in the Region // Sovremennie Naukoemkie Tehnologii. Regionalnoe Prilogenie, 2014, No 4, pp. P37-42.

5. Luo Juan, Angelina N. Ilchenko. Dynamic Analysis of Coupling Relationship between Economic Development and Ecological Environment of Hubei Province. //International Journal of Business, Humanities and Technology, USA, Vol. 5, No. 2. 2015.

6. Luo Juan, Angelina N. Ilchenko. The Research on the Relationship between Economic Development and Environment Pollution in Hubei Province Based on Gray Model. // Sovremennie Naukoemkie Tehnologii. Regionalnoe Prilogenie, 2014, No 3, pp. 68-72.

7. Luo Juan, Ilchenko A.N, Empirical Research on Economic Growth and Environmental Pollution in Hubei Province Based on VAR Model. // Ekonomika i banki, Belarus, 2013, No 1, pp. 27-30.

8. Luo Juan, Ilchenko A.N. Research on Coordinated Development of Economic Growth and Ecological Environment in Hubei Province. http://vestnik-es.vlsu.ru/. (Electronic journal, No 1, 2014).

9. Luo Juan. The Research of Hubei Province (China) Economic Growth Influence on Environment Quality. // Sovremennie Naukoemkie Tehnologii. Regionalnoe Prilogenie, 2013, No 1, pp. 37-42.

10. Report of the Commission on Economic Results and Social Progress // Voprosi Statistiki. 2010. № 11-12; 2011. № 2-3. (www. stiglitz-sen-fitoussi.fr).

11. Xia Yanging. A Qantitative Analysis on China's Environment and Economic Growth. PhD dissertation. Dongbei University of Finance and Economics, 2010. 